
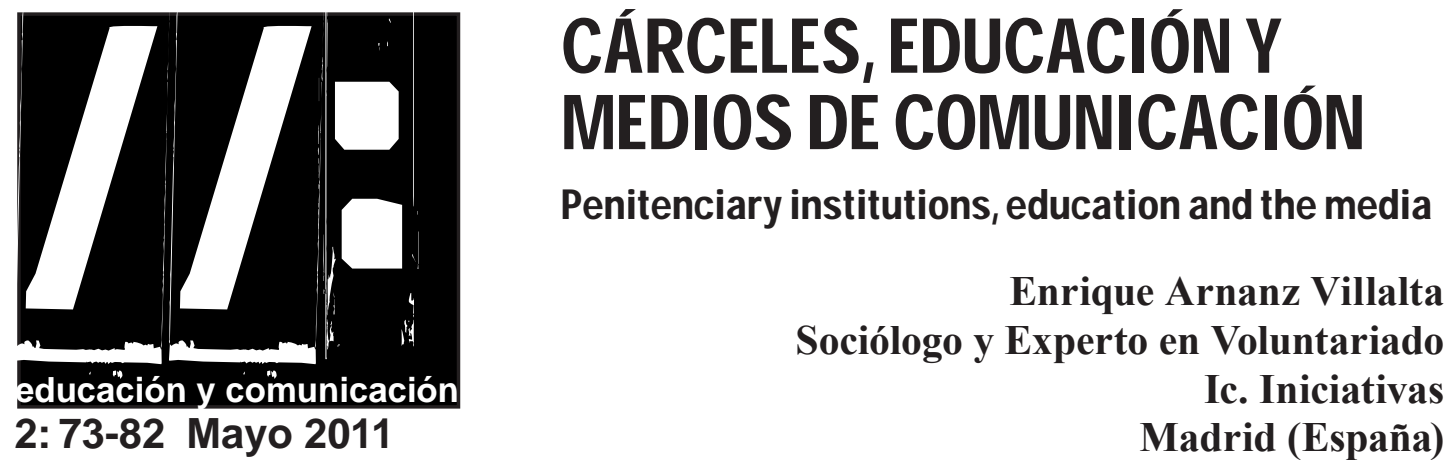

Resumen

Este artículo analiza, en plan de foto aérea, el tratamiento informativo que recibe -generalmente-en nuestro país "la cuestión penitenciaria", y las razones por las que son así las cosas.

Denuncia la identificación entre "lo morboso" y "lo publicable"; denuncia la omisión informativa; y reclama que sean conocidos y valorados muchos programas, presencias, historias de vida con clara proyección ejemplar y educativa que existen en la prisión, favoreciendo así la caída de estereotipos que daña la convivencia y dificultan la reinserción y normalización de la vida postpenitenciaria de las personas privadas de libertad.

Palabras claves: cárcel; violencia; privación de libertad; aislamiento social, medios de comunicación, periodismo espectáculo.

\title{
Abstract
}

This paper describes the informative treatment which the penitenciary question usually receives in our country and the reasons why it happens.

It is about the identification between the morbid and the question of what is considered as to be to published out, the article also denaunces the practise of omitting information, and claim to value and to acknowledge the importance of many social programmes, and life histories existing in prison, seeing them as a positive example and as a model to follow in order to erase the harmful stereotypes that affect the living inside prison and make the return to normal life for ex convicts more difficult.

Key words: prison, violence, liberty, social isolation , the media, journalism, penitenciary institutions.

Recibido: 07-03-2011 / Revisado: 31-03-2011 / Aceptado: 22-04-2011 / Publicado: 30-05-2011 


\section{II: Cárcel, Educación y Medios de Comunicación}

\section{La cárcel, ¿para qué?}

$\mathrm{L}$ a cárcel, aunque la pinten de rosa, le pongan música ambiental, disponga de piscina olímpica, polideportivo cubierto, salón de actos, televisión de plasma en alguno de sus departamentos, habitaciones bien ambientadas para las comunicaciones íntimas, comida de Ramadán para los islamistas, dieta blanda para quienes hayan sufrido problemas digestivos, aula de informática, biblioteca, talleres ocupacionales, escuela reglada, posibilidad de acceso a la Universidad, algunos talleres productivos, guarderías muy bien equipadas en los centros donde hay mamás con niños, etc., la cárcel, a pesar de todos estos equipamientos y recursos -y no están enumerados todos los que disponen la inmensa mayoría de los Centros penitenciarios ordinarios en el estado español-, es una estructura de violencia y un mecanismo de castigo que la sociedad ha creado para aquellos que saltan los límites de lo legalmente tolerable.

El tiempo penitenciario hace mucho daño y vuelve muy vulnerables para reiniciar su vida posterior a la mayoría de las personas que, pasan años y años entre sus cuatro paredes, sometidos a tres condiciones que definen la identidad de la prisión:

En primer lugar, una férrea privación de libertad con lo que esto conlleva de sumisión; dependencia de las decisiones de otras personas; supresión real de derechos personales muy importantes (asociacionismo, libertad de expresión, libertad de movimientos...); predominio de los elementos de régimen sobre los de tratamiento; control absoluto sobre la persona; falta de intimidad; disciplina férrea; sanciones encubiertas, etc.

En segundo lugar, un mutilante aislamiento social con lo que esto supone de desinformación general; separación de sus familias, amistades y entornos a los que volverán más tarde; entrada en el abismo de "los primeros grados" en bastantes casos; condiciones de salud, a veces, nefastas; consagración de su condición de marginados y excluidos sociales, incluso desde el punto de vista de su ubicación y localidad; sistemas telemáticos, electrónicos, de pinchos y alambres..., para garantizar la seguridad de los centros y el aislamiento social de sus residentes; etc. En tercer lugar, el sometimiento de todos a un mismo y unívoco régimen disciplinar que es incuestionable, que lo regula y lo controla todo, que se materializa en miles de normas y reglamentaciones y que genera al cabo de poco tiempo de estar en prisión, psicologías tuteladas, protegidas, dependientes, inútiles, con una enorme incapacidad de autoorganización..., porque durante años se han acostumbrado a sobrevivir haciendo diariamente todo lo que les dicen; y siempre y continuamente les dicen el qué, el cómo, el cuándo, el dónde, el con quién y el con qué..., de lo que tienen que hacer.

Es una afirmación de manual asegurar que el modelo de prisión que tenemos establecido en España y en nuestra Europa "desarrollada" -es cierto que hay notables diferencias entre unos modelos y otros y que en esa escala de diferencias, el modelo español es uno de los más abiertos y posibilistas- la convierte en una estructura castigadora y en un "ecosistema de dolor" por lo que acarrea y supone de privación de elementos esenciales de la vida, identidad y naturaleza de las personas. Como estructura, es un ecosistema de sombras y oscuridades para todos o casi todos, porque no podemos olvidar nunca que, es voraz para el interno, pero también, para muchos de los profesionales que trabajan en ella. 


\section{1/: Cárceles, educación y medios de comunicación}

\section{La educación "cuasi-todopoderosa"}

No voy a entrar en el debate sobre lo verdadero o falso de un supuesto "reformismo humanizador" de la prisión; o sobre lo acertado o no de las teorías correccionalistas de la privación de libertad; o sobre la resocialización como ideología.

Y no lo voy a hacer, porque no es éste el lugar ni el sentido de este artículo; porque es un debate superado, de hecho, por la práctica, y que tiene mucho de nominalista; y porque desde el punto de vista de la educación y la transformación de las personas, quiero defender un principio ético para mí indiscutible y una constatación sociológica refrendada por cientos de casos que conozco. Por lo tanto, no hago ambas afirmaciones sólo desde "lo culto", sino también desde "lo vivido".

El principio ético indiscutible, es el siguiente: "nunca se le puede negar a nadie la posibilidad de cambiar; el día que neguemos dicha posibilidad, estamos negando la vida".

La constatación sociológica es ésta: después de más de 30 años de experiencia de trabajo en el sistema penitenciario español y conociendo otros sistemas penitenciarios de diferentes continentes..., he visto que la cárcel ha sido para algunos hombres y mujeres una oportunidad de cambiar, de descubrir caras de su vida y dimensiones de su personalidad desconocidas incluso para ellos mismos, de ser más dueños de su propio destino sintiéndose cada vez más capaces de pensar, decidir y actuar por sí mismos en orden a la transformación de su propia vida y de su entorno.

Mi conclusión es que la cárcel tiene condiciones de negación y destrucción, y encierra también, algunas condiciones reales de posibilidad.

No afirmo que sea "un espacio educativo, terapéutico y cultural"; pero sí me atrevo a afirmar que encierra, supone y oferta para un cierto número de internos e internas condiciones educativas, terapéuticas y culturales que bien aprovechadas, pueden jugar un papel positivo en el cambio de sus valores, de su personalidad y del análisis que hacen de la vida $\mathrm{y}$ de su vida.

Enumero algunas de "esas condiciones de posibilidad":

1-. La oferta de programas individualizados y colectivos de tratamiento que responden a necesidades y demandas reales de los internos e internas y que reúnen, como programas, suficientes garantías de continuidad, estabilidad, planificación y control de respuestas, implicación de los propios internos, etc.

2-. El desarrollo progresivo de programas especiales de preparación para la libertad que, desde un punto de vista integral -sociolaboral, emocional, encuentro con la familia, autoorganización de su tiempo, elaboración de nuevas redes sociales, etc.- favorecen y contribuyen a la difícil normalización de la vida, después de su estancia en prisión.

3-. La presencia de la calle y de la sociedad civil en la vida cotidiana de la prisión y en todo el proceso postpenitenciario, desarrollando -en coordinación con los profesionales penitenciarios-programas de todo tipo; estableciendo con los internos relaciones más normalizadas que las que suelen tener con los propios profesionales penitenciarios; gestionando con inteligencia iniciativas y recursos; favoreciendo en los internos el desarrollo de su inteligencia emocional; y ejerciendo una presión disidente, para que mejoren las condiciones de vida de los internos e 


\section{II: Cárcel, Educación y Medios de Comunicación}

internas. Hablamos de la cárcel como cuestión social.

4-. La existencia de profesionales penitenciarios, en todos los ámbitos, que creen en la posibilidad de cambiar de los internos e internas y que, desde su función profesional, se convierten en "facilitadores" cualificados de estos procesos.

No sabría decir si hay muchos o pocos; pero los hay y los que están en este escenario, en coordinación con los agentes externos que se hacen cada vez más presentes en todos los ámbitos penitenciarios, llevan el peso fuerte del cumplimiento de la función reinsertadora que constitucionalmente tiene la prisión en nuestro ordenamiento jurídico.

También existen profesionales penitenciarios quemados, obsesionados por el cumplimiento estrictamente formal de sus competencias y con una muy baja dosis de motivación para trabajar con calidad..., entendiendo que cumpliendo lo estrictamente necesario nadie les puede exigir ningún plus de nada. Estos profesionales hacen mucho daño, al ser y significar una resistencia grande a cambios necesarios que deben realizarse en beneficio de los privados de libertad. Y están frecuentemente en el origen de las noticias más negras que se publican sobre la cárcel y sus moradores...

5-. La existencia de un tratamiento informativo de lo penitenciario orientado a reducir o hacer desaparecer progresivamente los estereotipos sociales que existen sobre "los presos" y que tanto dificultan la normalización y el desarrollo en libertad de la vida de estas personas a facilitar su reinserción y a mejorar la convivencia cívica entre unos y otros.

Creo que un tratamiento informativo y científico de "la cuestión penitenciaria" sería una de las condicio- nes de posibilidad esenciales para mejorar la convivencia cívica y para reconocer en los privados de libertad su condición de ciudadanía y de sujetos de derechos.

\section{Prisión y tratamiento informativo}

1-. Creo que actualmente, los medios de comunicación social son en gran medida uno de los principales responsables, por acción y por omisión, de la "actitud anti" que existe en grandes sectores de la opinión pública acerca de "la cuestión penitenciaria”.

Insistiendo en buscar impacto y en captar la atención de los ciudadanos, se ofrecen repetidamente imágenes penitenciarias perturbadoras, anecdóticas y descontextualizadas.

Si las imágenes son negativas (murallas de cárceles llenas de pinchos y cámaras de vigilancia, conducciones policiales de presos, motines, violencia, noticias de juicios con voces ambientales de linchamiento...) se ratifica así la opinión social mayoritaria sobre "la maldad" de sus moradores.

Si las imágenes son positivas (un programa músico/ cultural, un evento deportivo, una salida terapéutica curiosa, la visita de un "famoso" a la prisión...), se presentan como iniciativas aisladas, anecdóticas y muy poco relevantes, puntuales..., trasmitiendo la idea de que los presos y las presas "también se entretienen", disfrutan de vez en cuando de una bocanada de aire fresco... y no lo pasan tan mal.

Lo más graves es "la omisión informativa". Normalmente, la cárcel "no existe", es una estructura de olvido social, ubicada en el extrarradio, a muchos kilómetros de las poblaciones y las ciudades, y situada 


\section{1/: Cárceles, educación y medios de comunicación}

a una "distancia solar" de las preocupaciones de los ciudadanos, porque hoy, en un modelo social como el nuestro, no existe aquello de lo que no se habla. Ni existe ni tiene relevancia. Por eso, en la cuestión penitenciaria mucho peor que lo que se dice es lo que se omite, lo que no se cuenta, lo que "no interesa comentar" habiendo sido la cuestión penitenciaria una de las realidades sociales que más ha cambiado en España en los últimos 25 años.

Soy consciente de que hago esta afirmación en el marco de una legislación penal absurdamente punitiva, porque aquí se ha legislado a golpe de televisión; y soy consciente, igualmente, de que la cuestión penitenciaria mantiene problemas políticos, orgánicos y funcionales muy graves (por ejemplo, la no transferencia de las competencias penitenciarias excepto en el caso de Cataluña; o el enorme poder que tienen los sindicatos penitenciarios, y su obsesión paranoide hacia la seguridad regimental o los ribetes que todavía perduran en muchos penitenciarios al valorar la presencia de la calle en la vida de la prisión como un cierto intrusismo...

A pesar de todo, el cambio ha sido impresionante en muchos campos -sobre todo en la consideración de la cárcel como cuestión social- y ese cambio no se ha visibilizado ni muchísimo menos, en la proporción que se ha dado. ¿Por qué? ¿Qué responsabilidad tiene la industria de la información en el ocultamiento de esta realidad? ¿Por qué no interesa, o interesa tan poco la lectura positiva de la cuestión penitenciaria? ¿Porqué, en muchas ocasiones, los medios informativos mantienen, agravan, refuerzan la agresión y el rechazo contra las personas que viven la experiencia de la cárcel? ¿Por qué no colaboran a construir ciudadanía desde un planteamiento más objetivo y real de la Información sobre "otras cosas" que también ocurren y que se dan en el ámbito penitenciario y que tienen una consideración y evaluación positiva?¿Por qué es noticia "lo malo" y no es noticia "lo bueno"?¿Por qué es noticia el delito que comete un interno que ha salido de permiso de fin de semana y no ha vuelto, y no lo es el que miles de ellos vuelven a su Centro Penitenciario respectivo?¿Qué tiene aquello de noticiable?

¡No podemos olvidar nunca que los medios de comunicación influyen por lo que dicen y por lo que no dicen!

2-. Sin embargo, los medios de comunicación social podrían ser unos formidables instrumentos de cambio, solidaridad y progreso respecto del medio penitenciario, si permitiesen la transparencia; si abandonasen la identificación entre "lo morboso" y "lo publicable"; si se esforzaran en la educación de valores diferentes y alternativos respecto a la exclusión social; si fueran capaces de visibilizar muchas cosas positivas que se hacen en los centros y que hay en las personas detenidas; y si dejasen de exacerbar bajos instintos al servicio de dudosos intereses.

En el escenario penitenciario se están llevando a cabo actualmente, programas interesantes e inteligentes que suponen un enorme esfuerzo de imaginación, creatividad y coraje, y que junto con otros factores están en la base de la normalización de la vida en libertad de, cada vez, más internos e internas. Resulta absolutamente destacable la presencia y las aportaciones de múltiples administraciones locales, regionales o nacionales, de universidades y fundaciones, consolidándose cada vez más el protagonismo de la sociedad civil en todos estos procesos. Se están desarrollando, y apenas se publicitan, 


\section{II: Cárcel, Educación y Medios de Comunicación}

programas ya validados de preparación para la libertad; de formación de emprendedores y para el autoempleo; de aprendizaje de nuevas tecnologías. Crecen las estructuras de acogida de ongs que avalan a internos e internas -muchos de ellos extranjeros- sin redes sociales ni familiares cercanas, y que les ofertan múltiples posibilidades ocupacionales y laborales. Existen dentro de algunos centros penitenciarios módulos especiales para discapacitados físicos y orgánicos; módulos de respeto, con un alto nivel de autogestión por parte de los propios internos e internas; comunidades y unidades terapéuticas para personas con serios problemas de tóxicos o con otras alteraciones graves de conducta; programas especiales de atención a agresores sexuales o con problemas de violencia doméstica. Se imparten en muchos centros cursos homologados del INEM sobre especialidades laborales muy variadas que garantizan posteriormente un título reconocido; casi dos mil internos e internas están matriculados en la UNED; más miles, todavía, acuden diariamente a la formación escolar reglada, al aprendizaje del castellano para extranjeros...

En unas estructuras de castigo como son las prisiones, se hacen muchas cosas, condicionadas ciertamente por el omnipresente régimen disciplinar, pero que en muchos casos son útiles, eficaces y eficientes para la vida y las necesidades de los internos e internas.

¡Es cierto, sin embargo, que es mucho más lo que queda por hacer que lo ya hecho, que hay que mejorar la calidad de lo que se hace y establecer controles de calidad sobre los programas y actividades que se desarrollan, que tiene que mejorar mucho más la coordinación entre los profesionales penitenciarios y los equipos externos..., y que las dificultades regimentales condicionan los resultados!

3-. Los medios de comunicación tienen un papel esencial que jugar en la configuración de una cultura diferente del análisis, entendimiento y apoyo que contrarreste el morbo y la violencia que existe contra "lo penitenciario" y contra la gente que ha sufrido la prisión. Los medios de comunicación tienen un papel preventivo y educativo fundamental en la cuestión penitenciaria.

Los profesionales y empresas de comunicación deben tener suma cautela en evitar que sus informaciones se conviertan en armas de guerra, y deben procurar no ser cómplices conscientes o inconscientes de conflictos y estereotipos que dificultan más todavía la recuperación de los derechos de las personas privadas de libertad y sus posibilidades de normalización intra y postpenitenciaria.

Ya sé que esto no es fácil, especialmente ahora cuando el periodismo espectáculo está cada vez más en boga (sobre todo en la TV), y este periodismo no es un terreno abonado para la ética y la educación. Periodismo espectáculo que llega a todos los sectores sociales, sobre todo a los menos educados y más fáciles de manipular. Periodismo espectáculo que mueve enormes intereses económicos e intereses políticos espurios, y que está en manos de un poder muy poco inclinado a movilizarse a favor de una información libre y responsable, que ayude a consolidar una democracia y una ciudadanía más y mejor educada y participativa.

Los medios de comunicación que peor se manejan en "la cuestión penitenciaria", son los que peor se manejan en la construcción de la ciudadanía. Los 


\section{1/: Cárceles, educación y medios de comunicación}

que necesitan colocar una portada absolutamente devastadora para asegurar el negocio; los que ofrecen crónicas cada vez más cortas y superficiales (poco más que titulares), donde no se explica nada, no se investiga nada, no se comprueba nada, los que a la hora de elaborar boletines informativos encadenan temas heterogéneos y de una importancia desigual, sin respetar los principios básicos de jerarquización y estructuración de las noticias; los que seleccionan como muy interesante noticia penitenciaria cualquier "happening" morboso relacionado con algún famosillo o la noticia de que un preso de ETA sale de permiso o tercer grado con autorización del juez pero dándose la noticia de tal manera que se estimula a pensar que dicho etarra se ha beneficiado de algún pacto oscuro entre políticos que se olvidan de las víctimas tanto como incentivan a los terroristas.

\section{Papel preventivo y educativo de los medios de comunicación en la cuestión penitenciaria}

Las cuestiones, los momentos y las realidades difíciles, necesitan buenos medios de comunicación y buenos profesionales de la información que conozcan el tema; los malos periodistas y los malos medios de comunicación -y aquí incluyo a los jefes y a las empresas- son un enemigo más cuando hablando de historias de vida olvidan el contexto y el pasado, o cuando en estos temas priman la superficialidad, el envoltorio atractivo o cutre, el impacto visual sobre el conocimiento y el rigor informativo... Y así, la "veracidad penitenciaria" pasa a ser lo que los medios informativos dicen que es verdad, aunque no sea cierto, y tiene uno la sensación -como dice Ignacio Ramonet- de estar asistiendo a un acontecimien- to en primera fila en el salón de su propia casa, sin tener la necesidad de plantearse ninguna pregunta ni de formular ninguna respuesta.

Parto de tres ideas fundamentales para definir, después, algunas tareas y responsabilidades de los medios de comunicación respecto a la "cuestión penitenciaria".

1-. Comunicación no equivale sólo a información de noticias o hechos y a su comprensión. La información no puede reducirse a una hemorragia de noticias y sucesos imposible de entender y gestionar mentalmente. En el fondo de esto, subyace la comprensión de la información eminentemente desde la perspectiva del mercado.

La información no debería ser tratada como negocio, porque es demasiado importante para dejarla en manos del Mercado. Debe servir a la sociedad, no servirse de ella.

2-. Los medios de comunicación son hoy -y de aquí su enorme importancia- los principales trasmisores de cultura y conocimiento del otro. Según numerosas encuestas, la televisión es la fuente prioritaria de Información para la mayoría de los europeos.

3-. Ya hemos dicho de diferente manera, o hemos dejado suponer que el objetivo fundamental de los medios de comunicación debe ser informar con responsabilidad.

Pero también es cierto que existe una dosis importante de responsabilidad individual ciudadana que depende de nosotros mismos, de nuestras propias actitudes, del uso que demos o queramos dar a los medios de comunicación que utilizamos. Y en este sentido, no podemos dejar de reconocer que en este momento de "demo esclerosis", de escasa movilización y participación cívica, cada vez se va 


\section{II: Cárcel, Educación y Medios de Comunicación}

configurando con más fuerza y extensión un público apático, conformista, indiferente, consumidor pasivo..., cada vez más peligroso para nosotros mismos. Un público que se deja llevar y que se cree de forma a-crítica todo lo que se publique con el envoltorio más escandaloso.

Ya sabemos que las líneas editoriales de los medios de comunicación masivos son impenetrables y tienen múltiples reticencias ante nuevas propuestas, sobre todo, ante aquellas que amenacen la rentabilidad económica de su dominadora posición en este escenario.

A pesar de todo, nos atrevemos a formular algunas ideas, sabiendo que éstas tendrán mejor aceptación en pequeños espacios (medios locales, medios de ONG, medios de ciertos organismos internacionales, medios alternativos, revistas electrónicas, nuevos medios digitales...) más que en las grandes corporaciones.

Creo que los medios de comunicación pueden y deben desarrollar "un periodismo preventivo":

a-. Preocupado por crear una conciencia social de ciudadanía inclusiva multicultural, que acepte las diferencias como un valor, que ponga por delante la relación de las personas con las personas más que la relación de las personas con las cosas; que sea disidente de un modelo social que identifica calidad de vida con cantidad de consumo; que haga caer en la cuenta de la enorme diferencia que existe entre "lo legal" y "lo justo"; y que en nuestro ámbito más concreto, nunca defienda el delito pero nunca niegue tampoco la posibilidad de cambiar a quien infringe la ley, o dicho de otra manera, que defienda al "delincuente" como persona y ciudadano.

b-. Periodismo preventivo que anticipe los aconteci- mientos, situaciones, las circunstancias que puedan desembocar más tarde en conflictos sociales, crisis de derechos humanos, problemas de convivencia..., difundiendo las claves que ayuden a comprender los motivos y las causas que como no se corrijan, desembocarán inevitablemente en dichas situaciones.

c-. Periodismo preventivo que ponga especial interés en informar y hacerlo bien, sobre los esfuerzos y programas que se están haciendo para conseguir la reinserción, presentando en este escenario a todas las 'partes implicadas', internos e internas, profesionales penitenciarios, sociedad civil...

d-. Periodismo preventivo que a nivel postpenitenciario presente y hable de los fallos (recaídas, reincidencias...) pero también, y sobre todo, haga una discriminación positiva informativa a favor de los esfuerzos exitosos personales, institucionales y de organizaciones que han conseguido que muchas personas normalicen su vida y se incorporen a la ciudadanía con conciencia cívica, aportando a través de estas informaciones los elementos de análisis que puedan ser útiles para la prevención de situaciones negativas similares.

Se trata pues, de informar antes, en y después de..., no sólo cuando ocurre el happening, siendo el conjunto de los tres tiempos el que puede ayudar a prevenir lo mismo en el futuro.

Educar significa enseñar a ser (actuar por sí mismos, elaborar su propio proyecto de vida personal...), enseñar a convivir (hacer cosas en beneficio de los demás, generar empatías, desarrollar la capacidad de ponerse en el lugar del otro), enseñar a formar parte de una sociedad (conscientes de que al no vivir solos debemos aprender a respetar las normas sociales, la heterogeneidad de usos y costumbres, de 


\section{1/: Cárceles, educación y medios de comunicación}

identidades, de comportamiento...), enseñar a habitar el mundo (participar activamente en la mejora de la vida comunitaria, superar las fronteras del propio país...).

Pues bien, creo que los medios de comunicación, como espacio de transmisión de valores, tienen la obligación ética de contribuir a la expansión de esta filosofía educativa.

En este sentido, necesitamos también un "periodismo educativo" en el ámbito penitenciario que:

-. Informe con normalidad del mundo de las prisiones, informe sobre esta realidad que afecta a miles y miles de personas..., para que nos importen al resto de la sociedad, porque hasta ahora no nos importan. Que informen con la idea de conseguir que estas personas que sufren la privación de libertad sean valoradas, sencillamente, como personas y ciudadanos. Y más aún, como sujetos educadores -ique pueden enseñarnos muchas cosas!- y como educandos.

-. Un periodismo educativo que ayude a quebrar la imagen del preso como contaminado y contaminante social; que no anatematice a sus familias ; que ayude y favorezca la convivencia con la sociedad cuando salen de prisión; que divulgue y hable de espacios de encuentro y redes sociales donde ellos tienen protagonismo; que hablen más del futuro que se les abre que del pasado que les condiciona.

-. Un periodismo educativo que dé la palabra a las personas que viven o han vivido esta experiencia, para que puedan expresarse y proclamar que, como cualquier ciudadano, tienen derecho a exponer sus opiniones y puntos de vista, tienen derecho a ser creíbles. Un periodismo educativo que sea voz de estos "sin voz".

-. Un periodismo educativo que muestre la capaci- dad de cambio de muchas de estas personas, a pesar de sus condiciones e historias de vida adversas. Un periodismo que convierta la prisión en escaparate público de iniciativas y proyectos llenos de posibilidades de inclusión social y de realidades ya eficaces. -. Un periodismo educativo que cree opinión positiva sobre la identidad, la vida y el futuro de quienes han vivido la experiencia dolorosa de la privación de libertad. Y cuando decimos esto, nos referimos a todos, sea cual sea su delito, sea cual sea la línea roja que han saltado.

En este sentido, los medios de comunicación tienen la obligación de no hacer discriminación -hablando de posibilidades de cambio- de nadie, aunque reconociendo que existen violencias y comportamientos delictivos especialmente gruesos y repugnantes para la sensibilidad ciudadana. Pero el principio ético de "nunca se puede negar a nadie la posibilidad de cambiar" tiene que ser una convicción en todos los que trabajan en este medio y en quienes tienen el deber de informar "educativamente" sobre él.

\section{Referencias}

Arnanz Villalta E. (1989).Cultura y prisión. Madrid: Popular.

Bernabé Fraguas J. (2009).El periodismo preventivo y los observatorios de medios. Madrid: Catarata.

Calaf, R.M. (2008). El papel y la responsabilidad de los medios de comunicación en la construcción de la paz y el entendimiento intercultural. Madrid:Los retos del siglo XXI: Arnanz Villalta E. (2009). Ciudadanía y Globalización; una reflexión desde el Tercer Sector. Documentos para el debate de la Fundación 


\section{II: Cárcel, Educación y Medios de Comunicación}

Esplai.3; 10-60.

Marhuenda Fluixá A. (2006). ¡Coge la lupa! El sur en los periódicos. Cuadernos Cristianismo y Justicia. 139; 5-31.
Puig JM. (2008).Educació per a la Ciutadania. Aprenentatge servey. Centros i Entorn. Barcelona: Proyecto piloto impulsado por el Departamento de Educación de la Generalitat de Catalunya.. 